\title{
O TECIDO CIRCENSE: FUNDAMENTOS PARA UMA PEDAGOGIA DAS ATIVIDADES CIRCENSES AÉREAS
}

Marco Antonio Coelho Bortoleto

Daniela Helena Calça

\section{Resumo}

Este artigo disserta sobre o tecido circense, uma modalidade aérea cuja prática vêm transcendendo o ambiente do circo de lona e das escolas especializadas nesta arte e desperta interesses principalmente dentro de academias, clubes e, principalmente, de universidades, conforme observado na faculdade de educação física da Unicamp. Através de uma revisão bibliográfica, da experiência adquirida e da consulta em fontes on-line, apresentamos uma classificação elaborada de acordo com as diferentes amarrações e formas de utilização, além de discutir o processo pedagógico que envolve o ensino desta modalidade expondo as principais travas (ou chaves), figuras e quedas. Finalizamos o manuscrito expondo as noções básicas de segurança, cuidado com os equipamentos e com a preparação corporal específicos para a prática do tecido.

\section{Palavras-Chave}

Tecido circense; Pedagogia circense; Educação Física.

\section{THE CIRCUS STILT: THE PEDAGOGICAL FUNDAMENTS OF THE CIRCUS AERIAL ACTIVITIES}

Marco Antonio Coelho Bortoleto

Daniela Helena Calça

\begin{abstract}
The circus stilt: The pedagogical fundaments of the circus aerial activities. This article discuss the circus silk, an aerial modality with is now transcending the tent environment of the circus as well the circus school, and calling the attention of the universities (like the College of Physical Education of the State University of Campinas - UNICAMP), gyms and clubs. By reviewing the literature and the on line information, we now present a classification developed according to the different approaches and ways of practice, besides we discuss the pedagogical process that brings the teach of this modality withing its main keys, pictures and fallings. We finalized the manuscript exposing notions of security, equipment preservation and the specific body preparation for this practice.
\end{abstract}

\section{Key-Words}

Circus silk; Circus pedagogy; Physical Education. 


\section{INTRODUÇÃO}

O tecido é uma modalidade aérea circense, também denominada tecido acrobático, tecido aéreo ou tecido circense. Ao contrário de outras centenárias modalidades do circo, como o malabares, as acrobacias e o trapézio, o tecido apresentou seu desenvolvimento nos últimos anos (BATISTA, 2003; CALÇA; BORTOLETO, 2007).

Sobre a história desta prática, Desiderio (2003), traz um relato expressivo da historiadora de circo, Alice Viveiro de Castro, no qual relata que quando esteve no festival Internacional de Acrobacias de Wuqia (China), em 1999, foram expostos alguns desenhos orientais apresentados por uma pesquisadora da escola de Circo de Beijin, com performances em grandes panos nas festividades dos imperadores da China por volta do ano de 600 d.C., utilizando a seda como tecido da época. Ainda segundo Desiderio (2003), no ocidente, um dos relatos mais antigos é uma experiência nas décadas de 1920 e 1930, em Berlim (Alemanha), por alguns artistas que realizaram movimentos com as cortinas de um cabaré.

Não se sabe ao certo quem o inventou, mas se acredita que o tecido é uma extensão do trabalho de corda lisa, uma modalidade que antigamente era de sisal e atualmente é de algodão (esta última confere maior flexibilidade e conforto durante as travas). Por sua vez, parece que as performances na corda surgiram das evoluções realizadas pelos artistas quando subiam ao trapézio, ou até mesmo durante a instalação (montagem) do circo, na qual se utilizam as cordas para subir e descer das alturas.

Por outro lado, alguns relatos indicam que foi na França que o tecido circense foi aprimorado após pesquisas com diferentes materiais (cordas, tecidos, correntes, etc.), realizadas pelo francês Gèrard Fasoli nos anos de 1980 (DESIDERIO, 2003). Neste período, chegou-se à utilização de um material bastante resistente no comprimento e, ao mesmo tempo, com elasticidade na largura, o que lhe confere grande plasticidade e leveza. Este moderno material denomina-se liganete. Possivelmente existam outras ligas sintéticas que podem ser utilizadas para esta prática. No entanto, o mais importante é que este material suporte o peso do praticante multiplicado até quatro vezes (aproximadamente).

A inexistência de regras e a necessidade de inovar e criar, típicas das artes cênicas, fez surgir diferentes formas de prática do tecido na modernidade. Deste modo, a forma de fixar (amarrar) o tecido, assim como a altura, pode variar, e estes fatores influenciarão os tipos de travas (ou chaves), truques e quedas que poderão ser executados. Geralmente, o tecido é fixado acima dos 4 metros de altura (até 12 aprox.), mas vale ressaltar que um trabalho de iniciação nesta modalidade pode e deve ser realizado a poucos 
metros de altura, o que oferece maior segurança para o aprendiz. Gradativamente, e à medida que o praticante for se desenvolvendo e adquirindo qualidades físicas, técnicas e atitudinais (confiança, etc.), a altura das evoluções pode ser implementada.

De acordo com uma pesquisa realizada por Batista (2003), a prática do tecido aparece em diferentes contextos (espaços), não apenas debaixo da lona do Circo tradicional, mas também em academias, teatros, escolas, universidades, boates, clubes, dentre outros, e também com distintos objetivos. Bortoleto e Machado (2003) distinguem os três principais âmbitos de aplicação das atividades circenses: recreativo, educativo e profissional. Podemos dizer que o tecido circense já é praticado nestas três perspectivas e seus praticantes, geralmente, são pessoas que se apaixonam pela beleza e plasticidade desta modalidade, independentemente do objetivo de transformar-se num artista.

Dos aparelhos aéreos mais tradicionais das artes circenses (trapézios e suas variações, lira, bambu, corda indiana, argola olímpica etc.), o tecido é um dos aparelhos de mais fácil aprendizagem, sobretudo porque o material se molda ao corpo e se adapta de acordo com as características do praticante. Já os outros aparelhos, como o trapézio e a lira, por exemplo, exigem maior força e domínio corporal e também exigem que o corpo do praticante se molde ao aparelho, beneficiando, portanto, os que têm mais flexibilidade e força.

A prática do tecido circense dentro do ambiente universitário, e em especial no Instituto de Artes Cênicas (IA) e na Faculdade de Educação Física (FEF) da Universidade Estadual de Campinas (UNICAMP), tem sido observada com freqüência e despertado interesses, inclusive em alunos de outros cursos, como filosofia, física, letras, além da dança e da educação física. Segundo Desiderio (2003), o tecido circense chegou à faculdade de Educação Física da Unicamp no ano de 2000, através de uma aluna do Instituto de Artes, Beatriz Evrard. Desde então, foram oferecidos vários projetos de extensão, sendo que o primeiro curso foi oferecido pelo grupo Ilinx, em 2002.

Além dos projetos de extensão, foram realizados nos últimos anos diversos trabalhos de conclusão de curso e pesquisas de iniciação científica sobre este tema, como é o caso de Desiderio (2003) e Serra (2006) do curso de Educação física, Elisângela Carvalho Ilkiu (2005) e Cleonice de Paula Ferreira (2006) do curso de dança, dentre outros. Atualmente, a prática do tecido vem sendo observada dentro do curso de extensão universitária "Encontro Aberto de Circo", na Faculdade de Educação Física. 
A intenção deste trabalho é de orientar os profissionais que desenvolvem a prática do tecido circense nos distintos ambientes mencionados. Para tal, pontuaremos os principais tipos de tecido (tecido liso, doble tecido, tecido marinho e variações), e exporemos a seguir os tipos de amarrações e as técnicas principais de travas, assim como noções básicas de segurança com o equipamento e o corpo. Tais fundamentos permitirão, no futuro, avançar no estudo da pedagogia das atividades circenses.

\section{CLASSIFICANDO E CONCEITUANDO OS DIFERENTES TIPOS DE TECIDO}

Como acabamos de relatar, embora haja indícios de que a prática do tecido tenha raízes seculares, o desenvolvimento e aperfeiçoamento das técnicas e materiais utilizados nesta modalidade são recentes. Apesar da popularidade do tecido no Brasil - país que forma grande parte dos melhores artistas do mundo, ao mesmo tempo em que abriga milhares de praticantes sem o objetivo artístico -, poucas são as referências que analisam de forma criteriosa os diferentes formatos de tecidos e as técnicas básicas utilizadas.

A falta de uma metodologia específica, a confusão terminológica e conceitual, além da quase inexistente produção científica sobre o assunto, dificulta o intercâmbio de conhecimentos entre os especialistas, assim como o desenvolvimento de um processo de ensino-aprendizagem de qualidade. Pensando nesta problemática, estudamos a seguir os diferentes tipos de tecidos e suas peculiaridades.

\section{TECIDO LISO}

Consiste num pano de 20 a 26 metros aproximadamente, fixado pelo meio em estruturas de 5 a 10 metros de altura aproximadamente. Desta forma, o tecido fica dividido em duas partes iguais, que serão utilizadas para executar diferentes travas (ou chaves), figuras e quedas.

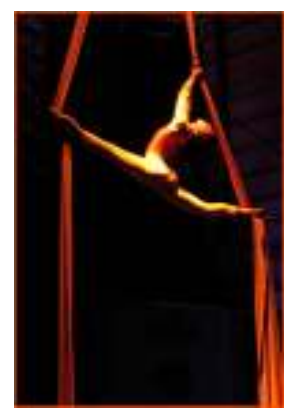

Figura 1 - Performances em Tecido Liso. 


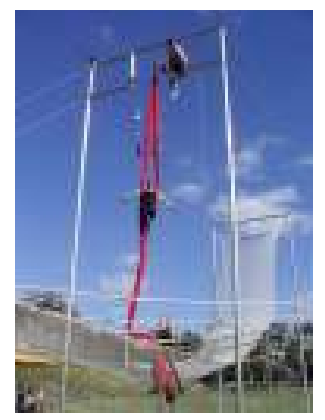

Figura 2 - Tecido Fixado em um Pórtico.

\section{TECIDO MARINHO}

É um tecido igual ao descrito anteriormente e difere no modo de fixação (amarrar). Ao invés de prender ao meio, prendem-se as duas extremidades separadas, a uma distância que pode variar conforme a preferência do praticante (aproximadamente 2-3 metros). Consequentemente, utiliza-se a parte central do tecido para a execução dos truques e acrobacias. Sua utilização é semelhante à outra modalidade circense, denominada Corda Marinha.

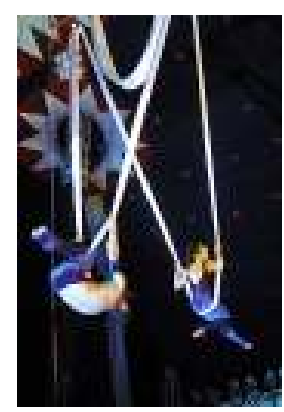

Figura 3 - Dois Tecidos Marinhos Simultâneos.

\section{DOBLE TECIDO}

Modalidade similar ao tecido liso, em que a performance é executada por dois artistas simultaneamente. Nela, além dos movimentos típicos do tecido normal, executados individualmente ou em dupla (Figura 4), podem ser realizadas portagens similares ao Doble Trapézio (Figura 5). 


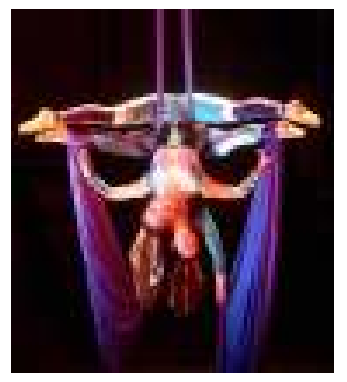

Figura 4 - Doble Tecido.

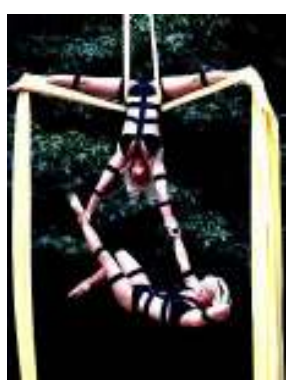

Figura 5 - Doble Tecido com Portagem.

\section{TECIDO AO VÔO}

Modalidade semelhante à Faixa circense, com fixação parecida à do tecido liso, na qual o praticante se prende à extremidade (as pontas que estão soltas) do tecido de diversas maneiras no solo e realiza vôos (balanço), giros, travas, pranchas e apoios invertidos, tracionados por um moitão (manual) ou guincho (automático). As travas geralmente são realizadas nos braços, punhos, mãos e pernas. Também existem performances realizadas em dupla. No caso do uso do moitão, seja com tração de motores ou manual, o acrobata varia a altura do aparelho em respeito ao solo, o que aumenta as possibilidades de truques. Em alguns casos, utilizam distorcedores (giros) na fixação do tecido para que o mesmo não enrole durante a performance.

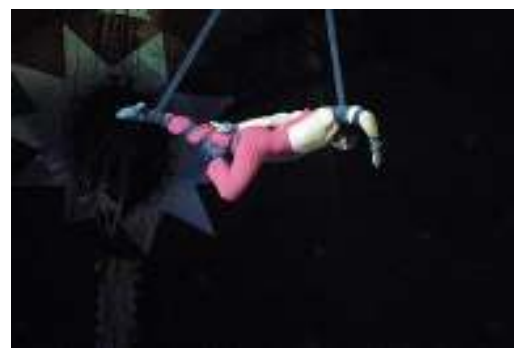

Figura 6 - Performance em Tecido Estilo Faixa. 


\section{VARIAÇÕES DE ACORDO COM A CRIATIVIDADE}

A maleabilidade e a plasticidade do tecido permitem inovações nas formas de amarrá-lo e utilizá-lo, que variam de acordo com a proposta e a criatividade do artista. Por conseguinte, são inúmeras as maneiras de exploração artística deste aparelho. As Figuras 8 e 9 ilustram uma performance do grupo inglês Viva Aerial Dance, que utiliza o tecido amarrado na forma de uma gota, podendo até mesmo variar o número de gotas feitas no mesmo tecido.

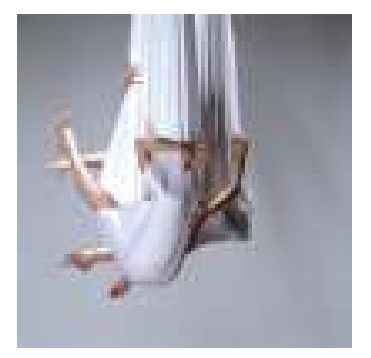

Figura 7 - Espetáculo da Cia. Viva Aerial Dance.

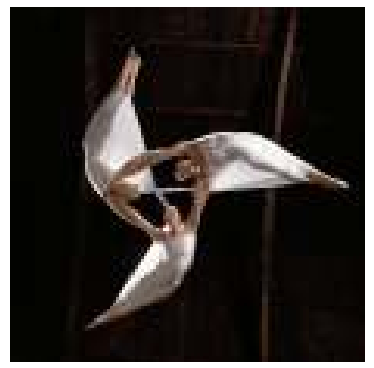

Figura 8 - Cia Viva Aerial Dance.

\section{INDICAÇÕES PARA O PROCESSO PEDAGÓGICO PARA O ENSINO DO TECIDO COMO AMARRAR O TECIDO?}

O tecido pode ser fixado de várias maneiras: pode ser diretamente em uma viga, guincho ou utilizando-se de fitas de rapel, faixas, triângulo de ferro, mosquetões ou anilhas metálicas. Independente do recurso empregado, o importante é que ele ofereça ao usuário total segurança.

A amarração mais utilizada é o "nó de porco" (Figura 9). Neste caso, deve-se dividir o tecido ao meio, segurar o tecido próximo à extremidade que será amarrada, realizar em uma das partes uma volta para cima de maneira que forme uma pequena gota e na outra parte do tecido, realizar uma volta para baixo. A seguir, devem-se unir as duas gotas e passar uma fita de rapel por dentro delas. Finalmente, fixar esta fita em uma estrutura metálica unindo suas extremidades com uma anilha ou um mosquetão. 


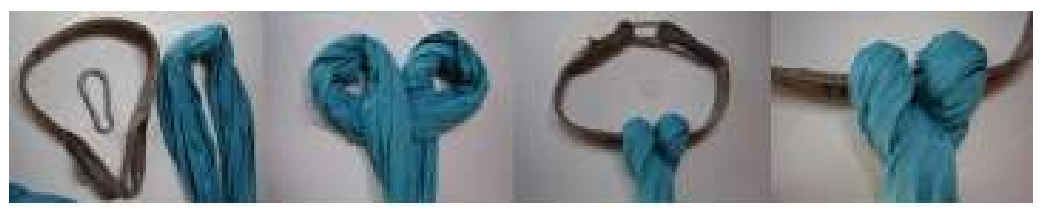

Figura 9 - Amarração nó de porco.

Outra forma comum de fixar o tecido é direto em uma estrutura (triângulo, barra ou viga que não forneça atrito), denominada "amarração simples" (BATISTA, 2003). Neste caso, divide-se o tecido ao meio, passa-se por cima ou dentro da estrutura desejada, forma-se uma pequena gota, e em seguida, deve-se passar as duas pontas completamente por dentro desta gota, estirando o tecido até que o nó se feche e mostre firmeza (Figura 11). Em ambos os casos é recomendável que a estrutura (ou viga) onde o tecido é fixado seja recoberta por algum tipo de material (mangueira de bombeiro, borracha, lonas, etc.) que minimize o atrito e, portanto, evite que o tecido se rompa.

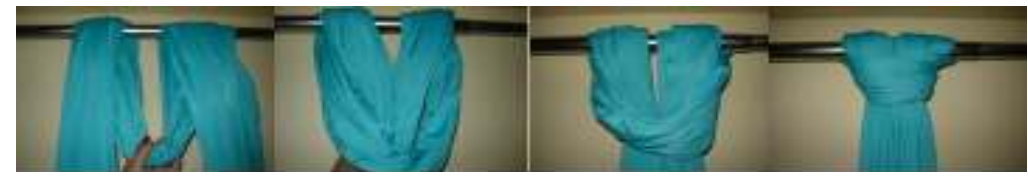

Figura 10 - "Amarração simples” direto na estrutura.

\section{COMO SUBIR NO TECIDO?}

Há diversas maneiras de se subir no tecido. Elas variam de acordo com a força e o domínio corporal do praticante. A maneira mais comum de subir é através da trava simples. Esta técnica pode ser descrita da seguinte forma:

a) posicionar-se de frente para o tecido;

b) segurá-lo com as duas mãos na altura dos olhos;

c) a partir de um movimento circular com uma das pernas de fora para dentro enrolar o tecido nesta perna;

d) elevar o joelho o mais alto possível e flexionar o pé (posição flex);

e) fazer força nos braços para sustentar o corpo por alguns segundos;

f) elevar a outra perna e pisar no tecido que está sobre o pé flexionado, de modo que ele fique bloqueado entre os pés;

g) deslizar os braços para cima e segurar novamente o tecido com as mãos;

h) soltar levemente a trava entre os pés e realizar a flexão das pernas e dos joelhos, de modo a deixar o tecido deslizar entre as pernas e os pés; 
i) realizar novamente a trava do tecido entre os pés, porém, em uma altura superior à primeira. E assim sucessivamente.

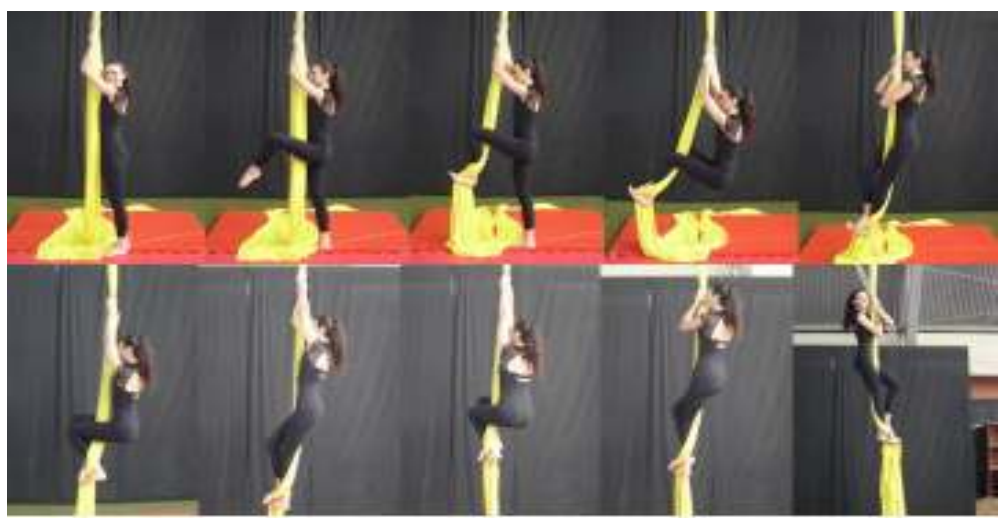

Figura 11: Seqüência de movimentos da subida simples no tecido.

Desta forma, o movimento de ascensão do tecido se assemelha aos movimentos de uma minhoca andando: eleva os joelhos, trava os pés, estende as pernas, eleva os joelhos, trava os pés, estende as pernas, e assim por diante.

Um exercício simples que pode ser proposto ao aluno, para assimilação da trava do tecido nos pés para a subida simples, é a pressão de uma bolinha de tênis entre os pés. Para executá-lo, deve-se posicionar a bolinha sobre o dorso de um dos pés e realizar pressão com o outro pé sobre a bolinha. Pode-se, também, utilizando o próprio tecido solto no solo, ou mesmo lençóis, fazer exercícios que permitam ao aluno aprender a pressionar o tecido entre os pés e a sentir a estabilidade da trava. É recomendável praticar esta seqüência de movimentos no solo antes de iniciar a ascensão.

Outras formas de subida no tecido podem ser consultadas no trabalho de Batista (2003), assim como no manual elaborado por professores especialistas e organizado pela Federação Européia de Escolas Profissionais de Circo (FEDEC, 2006).

\section{FIGURAS E TRAVAS BÁSICAS}

Após aprender o movimento da subida simples e sentir que o tecido já pode ser travado entre os pés, o praticante poderá iniciar o aprendizado de figuras e travas básicas, o que inaugurará seu repertório elementar de técnicas desta modalidade. 
De acordo com a experiência prática e os estudos realizados sobre esta modalidade e suas técnicas, podemos pensar em uma seqüência pedagógica de progressiva dificuldade para o ensino dos truques no tecido. Assim, as primeiras travas que podem ser exploradas e aprendidas são as dos pés e tornozelos, depois as da cintura e axila, logo as travas de quadril e, por último, a trava na curva da articulação do joelho, que é considerada, por muitos, a de maior complexidade e dificuldade.

\section{CRISTO}

A primeira figura a ser realizada pelos praticantes que se iniciam na prática do Tecido é o Cristo, como afirma Serra (2005). Para executá-la, basta estender os braços para cima, separar as duas partes do tecido, passar um braço para frente entre os tecidos e depois o outro, mantendo-os em abdução (braços abertos na altura dos ombros, forçando-os para trás). O cristo pode ser uma figura de descanso, e também uma forma de descer do tecido. Para descer, estando nesta posição, basta deixar o tecido deslizar bem devagar entre os pés controlando o peso do corpo e a trava nos pés. Caso descenda rápido demais, o praticante pode ferir-se com pequenas queimaduras ocasionadas pelo roce do tecido com os pés e mãos.

\section{TRAVAS DE PÉ}

Uma das primeiras travas (ou chaves) aprendidas que envolve os pés é o LOCK (ou trava de pé). Este movimento é realizado da seguinte maneira: a) após a subida simples, segurar firme o tecido com as mãos na altura dos ombros, posicionando as pernas estendidas e deixando a trava do tecido nos pés; b) flexionar os quadris, de modo que o corpo fique em forma de V; c) sustentar a perna de baixo e com a perna de cima empurrar com o pé o tecido na altura dos joelhos; d) realizar uma volta de fora para dentro no outro pé de maneira que forme um nó no meio deste.

A partir do LOCK, é possível montar várias figuras como: a secretária, negativa, morcegão, enrolada, anjo, casulo, avião (BATISTA 2003 e SERRA 2006).

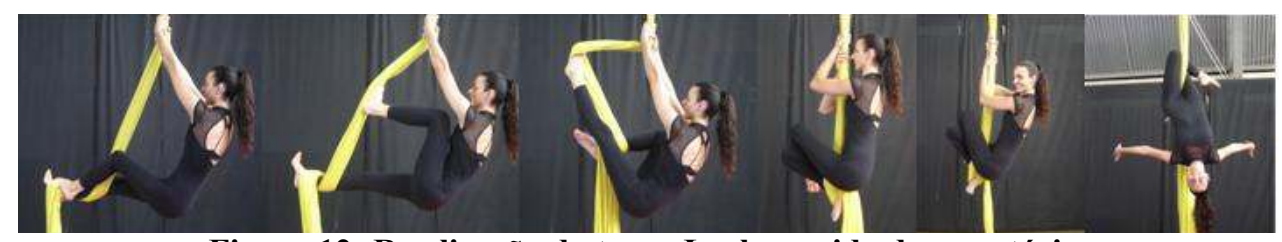

Figura 12: $R$ ealização da trava Lock seguido da secretária.

Para executar a Secretária, por exemplo, deve-se partir do LOCK em um dos pés, cruzar a outra perna por cima, ir abaixando até que as pernas terminem de dobrar. Logo, deve-se posicionar o tecido sobre o 
joelho da perna que está cruzada, segurar o pé com a mão oposta e devagar, ir descendo o tronco até ficar em posição invertida. Quando sentir segurança na posição, a mão pode ser solta e o pé da perna cruzada ficará livre para se movimentar.

\section{TRAVA DE CINTURA}

Uma figura que utiliza a trava da cintura é o Portô (ou portor, nome da figura, mas que também pode ser utilizada para portagem de outro acrobata).

a) Com os tecidos separados, sustentar o corpo com os braços ou pelas mãos, de forma a deixar as pernas livres para enrolar, com movimento circular de fora para dentro, com uma parte do tecido em cada perna;

b) Realizar o Cristo;

c) inclinar o tronco para um dos lados, passar o braço por trás e pelo meio dos tecidos e empurrar o tecido mais distante para trás, com a outra mão agarrar este tecido que está sendo empurrado, puxar para passar pela cabeça e pelo outro braço, de maneira que forme um X nas costas e o tecido passe bem abaixo das axilas;

d) Com as mãos, segurar o tecido na altura da cabeça e realizar um movimento de esquadro para trás com as pernas afastadas (elevação das pernas, inclinação do tronco para trás e para baixo). (Figura 13), Esta figura é chamada de portô, no entanto, há um outro portô (portô simples), que se inicia diretamente do movimento do cristo, faz-se o movimento $\mathrm{X}$ nas costas e realiza-se o esquadro para trás e para baixo.

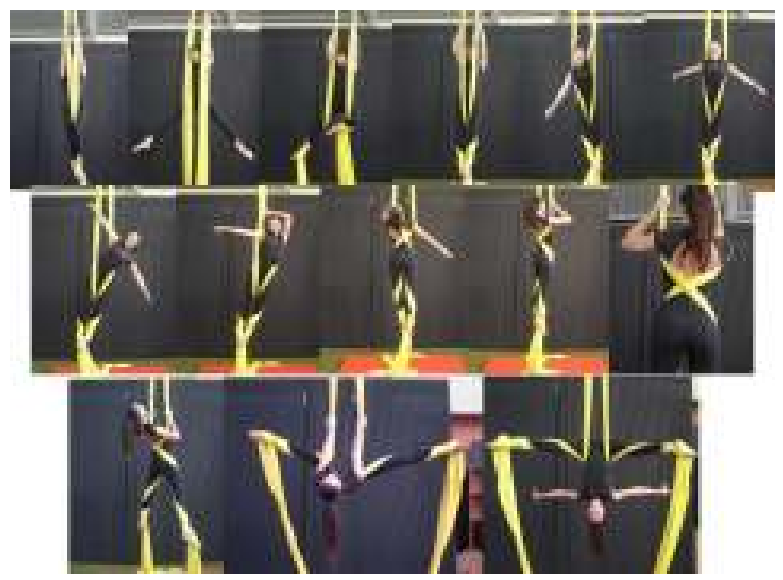

Figura 13. Montagem do Porto. 


\section{TRAVA DA AXILA}

Uma figura que utiliza a trava nas axilas é a Borboleta. Sua montagem consiste em segurar os tecidos abertos, passar o corpo por dentro dos tecidos e realizar um esquadro para trás com as pernas afastadas, até deixar o corpo na posição invertida, as pernas se enrolam no tecido de fora para dentro e formam uma trava com os pés flexionados. As mãos deslizam-se pelo tecido, de modo a dar uma volta atrás do corpo, na altura dos ísquios do quadril. Deslizar novamente, trazendo o tecido para frente do corpo e fazendo duas voltas na altura do peito. Após as voltas, as mãos deslizam até estender os braços e segurar firme o tecido. Soltar a trava com os pés, fazer força com as pernas para levantar o corpo que estava invertido até a posição de pé. Assim, os braços ficam livres para movimentações.

Para desmontar a borboleta, devem-se segurar os tecidos na altura da cabeça, realizar o movimento de esquadro novamente, com as pernas afastadas, desvirar as voltas que estavam na frente do corpo (no peito). Logo, pode-se realizar uma descida nesta posição ou retornar para o tecido na posição de pé e desfazer a volta que estava atrás do corpo, retornando para a trava da subida simples.

\section{TRAVA DO QUADRIL OU HIP LOCK, OU AINDA CHAVE DE CINTURA (BATISTA 2003)}

A trava de quadril é a que possibilita as primeiras quedas. As travas já descritas possibilitam, geralmente, figuras estáticas. A trava de quadril, ou também conhecida como Hip Lock, é montada da seguinte maneira:

a) segurar o tecido na altura dos ombros;

b) posicionar o tecido do lado direito do corpo, com o joelho esquerdo;

c) buscar o tecido com um movimento parecido com a tesoura da capoeira. Ao pegar o tecido com o joelho esquerdo, flexionar o mesmo, aproximando-o do peito. Girar o corpo todo para a direita, de forma a travar o tecido nos quadris. Nesta trava, o corpo fica inclinado lateralmente em relação ao tecido, preso pelo quadril.

Através desta trava, é possível fazer a queda à frente, a bala simples, a bala dupla e a queda de joelho, dentre outras variações e combinações (BATISTA, 2003).

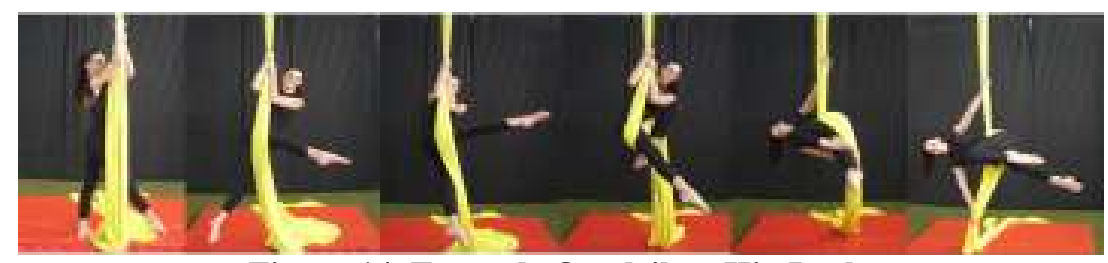

Figura 14. Trava de Quadril ou Hip Lock.

Conexões: revista da Faculdade de Educação Física da UNICAMP, Campinas, v. 5, n. 2, p. 72-88, jul/dez. 2007. 
TRAVA DA CURVA (SERRA, 2006)

A trava da curva é a mais difícil das detalhadas neste texto, pois exige que o praticante pressione o tecido e utilize-se apenas da curva da articulação do joelho. Por outro lado, esta é a trava que possibilita as quedas mais desejadas e admiradas, como a frente-lado-lado, a suiçaide, a queda da hélice, 1 e meia, 2 e meia, 3 e meia etc., espingarda, gota, dentre outras. Além disso, pode-se realizar subidas no tecido com a curva de joelho, conhecida como subida francesa: travar com a curva da articulação de um dos joelhos o tecido unido (fechado) ou com as duas curvas da articulação do joelho juntas, com os tecidos afastados (aberto). Também são possíveis descidas na curva com suas variações.

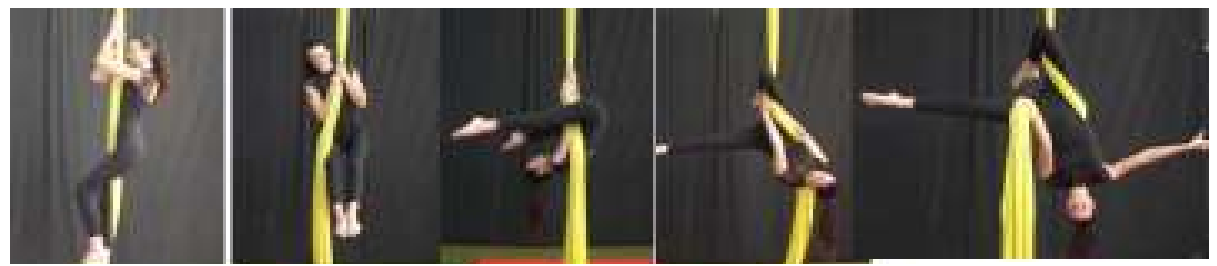

Figura 15. Trava da Curva (parte posterior da articulação do joelho).

\section{SUIÇAIDE OU FRENTE-LADO-LADO}

Segurar o tecido fechado com as mãos, deixá-lo do lado direito do corpo. Realizar um movimento de esquadro, elevando as pernas afastadas até inverter o corpo. Prender a curva direita no tecido, completar a volta nas costas com a mão esquerda, passar o tecido entre as pernas e dar 2 voltas na coxa esquerda. Colocar o tecido que sobrou no ombro esquerdo, segurar o tecido em cima da curva direita e subir o corpo até ficar na posição de pé. Com a mão direita, segurar o tecido acima da cabeça e, com a mão esquerda, segurar a sobra do tecido à frente, flexionar o joelho esquerdo, o qual será a trava da queda. Soltar a mão direita e agarrar o tecido que está sendo segurado pela mão esquerda, fazendo uma tração para ajudar a trava na articulação do joelho esquerdo.

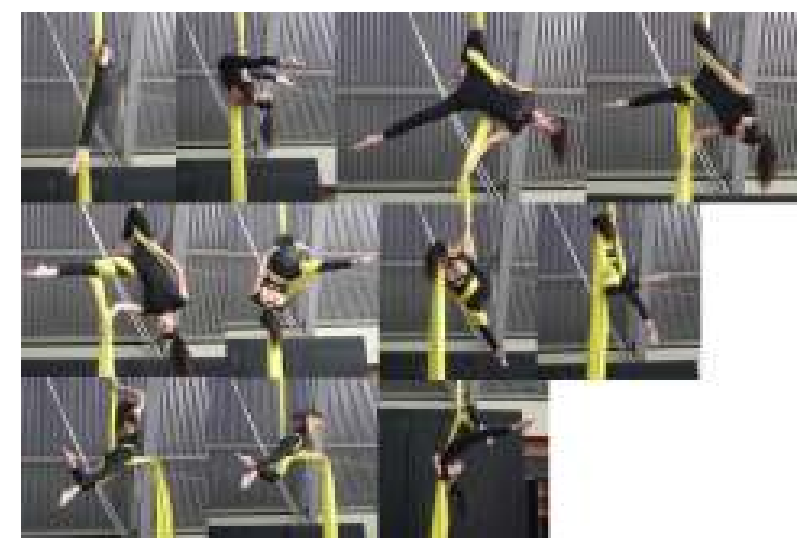

Figura 16. Montagem queda Suiçaide. 


\section{NOÇÕES BÁSICAS SOBRE SEGURANÇA, CUIDAdOS COM O EQUIPAMENTO E PREPARAÇÃO CORPORAL PARA A PRÁTICA DO TECIDO}

Pelo fato do tecido aéreo, como o próprio nome diz, estar suspenso a determinada altura do solo, e muitas vezes, sem o contato com o mesmo, algumas medidas de segurança devem ser respeitadas, para evitar acidentes ou, ao menos, minimizar suas conseqüências.

A primeira, e mais importante, é a verificação da instalação do aparelho e a vida útil das faixas, manilhas e cordas que suspendem o mesmo. Normalmente, cada artista realiza a fixação, manutenção e verificação do seu próprio equipamento. A manutenção e a checagem devem ser realizadas periodicamente. Aconselha-se a instalação de backups, ou seja, faixas extras de segurança (paralelas), para o caso de que a faixa primária de sustentação arrebentar.

A segunda medida é a utilização de acessórios que garantam a proteção em caso de quedas, como colchões de segurança. No caso de um aprendiz, o bom senso do professor (sensibilidade e experiência) é fundamental. É aconselhável realizar o inicio da prática a baixa altura, e paulatinamente, conforme a evolução do aluno, aumentar a altura.

Outra questão importante é, mesmo a poucos metros de altura, nunca saltar (abandonar) do tecido para descer, pois, às vezes, a noção de profundidade e altura pode ser confundida e gerar um acidente a partir deste falho na percepção espacial.

O tecido, assim como as Cordas circenses, costuma queimar (ferir a pele por conta do atrito) ou causar hematomas quando entram em contato com o corpo nas travas e outros truques. É por este motivo que o uso de roupas apropriadas, que cubram as axilas, a região abdominal, a cintura e as pernas (a maior superfície possível do corpo) ajuda a evitar as escoriações e os hematomas ocasionados pelo contato brusco com o aparelho. Outro aspecto é o uso de substâncias como o "breu", que podem proteger contra o suor das mãos e outras partes do corpo e, portanto, garantem a aderência desejada ao tecido.

Para todas as modalidades aéreas, o material deve ser de qualidade e, se possível, certificado, com capacidade para suportar cargas bem superiores à que os artistas impõem com seu próprio corpo. Atualmente, é recomendável utilizar cordas dinâmicas, semi-dinâmicas ou estáticas de alta resistência (tipo escalada), certificadas por fabricantes reconhecidos e especializados. O mesmo se aplica aos mosquetões, moitões, roldanas, cabos e todo o material utilizado. Conhecer estes equipamentos e saber 
reconhecer desgastes e problemas, assim como sua correta instalação, é fundamental para a prevenção de acidentes (ACAPTA, 2007).

Não podemos esquecer de que a adequada preparação corporal (condicionamento específico) para a prática dos aéreos é fundamental para a sua qualidade e para um desenvolvimento eficaz do processo de aprendizagem. Da mesma forma, a compensação postural e física para os excessos que alguns segmentos recebem deve ser tratada adequadamente, para evitar problemas a longo prazo.

O sistema de treinamento corporal é semelhante ao empregado na Ginástica Artística de competição, e deve buscar a maior especificidade possível, como sugerem os novos manuais editado pela FEDEC (2006).

Nas modalidades em duplas será fundamental manter uma excelente confiança e sincronismo entre os companheiros. Esta cumplicidade será garantia de segurança e êxito no trabalho.

Cabe destacar que paises como França e Austrália possuem leis federais que regulam as atividades artísticas, incluindo as circenses. Na França, em particular, toda apresentação em que os artistas se elevem acima dos 4 metros de altura devem ser acompanhadas por medidas de segurança especiais, como colchões de queda e lonas. Mesmo que não se apliquem tais regras em nossa sociedade, o entendimento dos sistemas e procedimentos de segurança devem ser de conhecimento de todos os praticantes e professores.

Devido ao fato de que as travas e figuras envolvem o corpo do acrobata no tecido e vice-versa, sugerimos que o tecido nunca seja afastado, mas mantido sempre perto do corpo durante as evoluções, criando uma situação de intimidade e maior percepção com o aparelho, condição que elevará o nível de segurança desta prática.

Enfim, estas são algumas medidas mínimas que podem ser tomadas pelos acrobatas aéreos, para prevenção de acidentes, visto o inerente risco da modalidade.

\section{CONSIDERAÇÕES FINAIS}

Esperamos que este artigo venha contribuir positivamente para a prática do tecido circense, modalidade que encanta e "arrasta" praticantes com diferentes objetivos, motivados pela plástica e estética e em 
diferentes ambientes e lugares.

Neste trabalho, focamos no ensino das técnicas apenas do tecido liso, postergando para outras oportunidades o detalhamento dos elementos básicos e das variações próprias às outras submodalidades do tecido.

Alguns trabalhos que foram consultados para o presente artigo apresentam figuras e seqüências fotográficas dos movimentos, o que facilita o processo de visualização e entendimento do movimento. Com isso, acreditamos que com a vivência prática o entendimento teórico dos movimentos se complete e contribua para a eficácia do processo de ensino pedagógico, para a conscientização e domínio corporal do acrobata e para sua própria segurança. Concluímos, reafirmando que "todo cuidado é pouco" diante de uma arte que envolve altura e movimentos complexos.

\section{REFERÊNCIAS}

AUSTRALIAN Association for Circus and Physical Theatre (Acapta). Safety code. Disponível em: $<$ http://www.acapta.net/03_safety/index.htm>. Acesso em: 10 fev. 2007.

BATISTA, N. S. O tecido circense como manifestação da cultura corporal: fundamentos técnicos e metodológicos. 2003. Monografia (Graduação) - Universidade Estadual de Maringá, Maringá, 2003.

BORTOLETO, M. A. C.; MACHADO, G. A. Reflexões sobre o circo e a Educação Física. Revista Corpoconciência, Santo André, n. 12, jul./dez. 2003.

CAlÇA, D. H.; BORTOLETO, M. A. C. La tela circense. Revista Zinkolika, Barcelona, v. 11, p. 23-24, 2006.

DESIDERIO, A. Corpos suspensos: o tecido circense como possibilidade para a Educação Física Escolar. 2003. Trabalho de Conclusão de Curso (Graduação) - Faculdade de Educação Física, Universidade Estadual de Campinas, Campinas, 2003.

EUROPEAN Federation of Professional Circus Schools (FEDEC). Pedagogical tools. Disponível em: $<$ http://www.fedec.net/fr/fedecuk2.html.>. Acesso em: 12 dez. 2006.

SERRA, C. S. Aproximando a Educação Física às artes cênicas: metodologia do tecido acrobático. 2005. Trabalho de Conclusão de Curso (Graduação) - Faculdade de Educação Física, Universidade 
Estadual de Campinas, Campinas, 2005.

Webs de consulta

www.aerialexperience.com www.circusperformer.com www.pinrodamacircus.com.br www.intrepidatrupe.hpg.ig.com.br www.vivaaerialdance.co.uk

Marco AntonioCoelho Bortoleto

Faculdade de Educação Física - UNICAMP

Daniela Helena Calça

Faculdade de Educação Física - UNICAMP

Referência do artigo:

ABNT

BORTOLETO M. A. C., CALÇA D. H. O tecido circense: fundamentos para uma pedagogia das atividades circenses aéreas. Conexões, v.5, n. 2, p. 72-88, 2007.

APA

Bortoleto, M. A. C., \& Calça, D. H. (2007). O tecido circense: fundamentos para uma pedagogia das atividades circenses aéreas. Conexões, 5(2), 72-88.

\section{VANCOUVER}

Bortoleto MAC, Calça DH. O tecido circense: fundamentos para uma pedagogia das atividades circenses aéreas. Conexões, 2007, 5(2): 72-88. 